\title{
James Halloran, o homem e o mito
}

\author{
José Marques de Melo'
}

\begin{abstract}
Resumo
James Halloran presidiu a IAMCR durante o periodo 1972-1990. Mesmo sem ostentar titulação acadêmica, conquistou prestigio internacional., Depois da aposentadoria, adotou postura discreta, recolhendo-se à vida privada. Mas sua trajetória no cenário mundial sempre provocou especulações, por ter sido o intelectual de notório saber que mais tempo permaneceu na liderança da nossa comunidade. Após o anúncio do recente funeral, sua memória tem sido reverenciada em todo o mundo, recolocando na ordem do dia as circunstâncias da sua mitica ascensão à vanguarda comunicacional. Na tentativa de elucidar esse paradoxo, o presente artigo resgata alguns aspectos particulares da sua biografia intelectual, inclusive as andanças pela América Latina.
\end{abstract}

Palavras-chave: Pensamento Comunicacional. História. Biografia. Inglaterra. Brasil.

\begin{abstract}
James Halloran served as IAMCR President during the period 1972-1990. In spite of having not academic titles, he gained international recognition. After retirement he adopted a discreet posture, seeking refuge in the private life. But his singular trajectory in the world community frequently was remembered for his singularity as intellectual of notorious knowledge that preserved the largest position in the communication vanguard. After announcement of recent funeral, his memory has been reverenced around world, putting again in the public agenda the circumstances of his .upgrade to the top of our academic community. In order to better understand this paradox, the present paper intends to rescue some particular aspects of his intellectual biography, including the itinerary accomplished throughout Latin America.
\end{abstract}

Key words: Communication Theory. History. Biography. Great Britain. Brazil.

\section{Resumen}

James Halloran ocupó la función de Presidente de IAMCR durante el periodo 1972-1990. Aunque no tuviera titulos académicos, conquistó reconocimiento internacional. Después de la jubilación, mantuvo postura discreta, recluso a la vida privada. Pero su emblemática carrera academica siempre provocó curiosidad por la condición de intelectual de notorio saber que más tiempo permaneció en la vanguardia comunicacional. Luego del anuncio reciente del funeral, su memoria viene siendo reverenciada alrededor del mundo, reubicando en la agenda publica las circunstancias de su larga permanencia en el topo de nuestra comunidad académica. Esta ponencia pretende contribuir para elucidar la paradoja, recatando aspectos singulares de su biografia intelectual, incluso el itinerario desarrollado en América Latina.

Palabras-clave: Pensamiento comunicacional. História. Biografia. Inglaterra. Brasil.

\footnotetext{
' Doutor em Ciências da Comunicação (Jornalismo) e Professor-Emérito da Escola de Comunicaçōes e Artes da Universidade de Săo Paulo (Brasil), foi Presidente da Asociación Latinoamericana de Investigadores de la Comunicación - ALAIC (1989-1992) e Vice-Presidente da International Association for Mass Communication Research - IAMCR (1992-1996). Dirige atualmente a Cátedra UNESCO de Comunicação na Universidade Metodista de São Paulo e preside a Sociedade Brasileira de Estudos Interdisciplinares da Comunicação - INTERCOM.
} 


\section{Paradoxo}

O mais longevo dirigente da comunidade mundial de ciências da comunicação faleceu na Inglaterra, os 80 anos de idade, no dia 16 de maio de 2007.

A notícia da morte de James Halloran circulou com rapidez, graças à velocidade da internet. Desta maneira, sua memória foi reverenciada simultaneamente em distintos quadrantes do planeta.

Sem ostentar os títulos que fizeram a fama de muitos intelectuais ungidos pela academia, ele conquistou a liderança dos seus pares, comandando durante 18 anos a mais representativa corporação internacional de cientistas da comunicação, a International Association for Mass Communication Research - IAMCR.

Fundada em Paris, em 1957, essa entidade vem contando com o respaldo institucional da UNESCO - Organização das Nações Unidas para Educação, Ciência e Cultura, em cuja sede acaba de se realizar o congresso comemorativo das suas Bodas de Ouro.

O que explica sua meteórica ascensão ao poder acadêmico, justificando a permanência duradoura no topo da nossa comunidade? Independente dos méritos pessoais e das habilidades diplomáticas, alguns elementos simbólicos influíram para configurar sua mítica trajetória, tornando indivisiveis as fronteiras entre o homem e o mito.

\section{Ascensão}

Diz a lenda que a ascensão de James Halloran foi iluminada pela estrela candente de Gardel e a consagração regida pela galáxia ofuscante de McLuhan.

Sua eleição para presidir a IAMCR deu-se em 1972, na cidade que imortalizou Carlos Gardel. A vitória em Buenos Aires era imprevisível e em certo sentido inconcebível, pelo perfil marcadamente anglófono, que distanciava do poder os candidatos potenciais.

A primeira fase da história da IAMCR (1957-1972) refletiu naturalmente o clima da guerra fria que ganhou corpo durante o período pós-guerra, traduzindo a disputa ideológica entre dois sistemas mundiais: capitalismo e comunismo. A entidade converteu-se, de modo inevitável, em palco de disputa pela hegemonia política. Liderada pelo grupo francófono, a corrente latina empalmou o poder, elegendo como 
primeiro presidente o diplomata francês Fernand Terrou (1957-1959). Ele foi imediatamente sucedido, num clima saudável de alternância politica, pelo liberal norte-americano Raymond Nixon, cuja gestão (1959-1954) foi mal compreendida e estigmatizada. Alguns segmentos mais radicais o consideravam equivocadamente um agente do imperialismo ianque.

Por tudo isso, a expectativa era de que o suiço Jacques Bourquin (1964-1972), fosse substituído por alguém do bloco latino, tendo em vista os conflitos precedentes.

A escolha de um autêntico inglês, em pleno território latino, para liderar a mais importante sociedade cientifica do campo comunicacional surpreendeu indubitavelmente. Este é um episódio ainda não plenamente esclarecido na vida da associação, cujos fatores reais ainda permanecem na bruma histórica.

De acordo com a versão mítica, na véspera da eleição, James curtiu músicas portenhas, dançando um tango em plena Corrientes, 348. Ao ser banhado pelos raios luminosos da estrela de Gardel, ele foi energizado para usufruir sucesso prolongado. Este só começou a fenecer 16 anos depois, quando Halloran enfrentou a ameaça de um tsunami latino. Dez anos depois da sua ascensão, a lAMCR se reunira em Paris (1982), então convertida em capital do tango. Segundo as cassandras, James deveria ter feito ali a atualização do ritual milongueiro, para melhor se adaptar aos cenários ainda imperceptiveis da globalização neoliberal.

Durante o tumultuado congresso de 1988, em Barcelona, jovens comunicólogos ibéricos, encorajados pela diáspora latino-americana e respaldados pelas minorias terceiro-mundistas, reivindicavam o fim do bilingüismo franco-anglófono. O reconhecimento do espanhol como lingua oficial da associação era questão inegociável.

Embalados pelo exercício tardio das liberdades democráticas, em regimes pós-autoritários, a nova geração questionava ainda a estrutura de poder vigente na IAMCR, denunciando o longo "reinado" de James Halloran. Graças à mediação eficaz dos anfitriões da Catalunha, a previsão de tormenta acabou se convertendo em ressaca.

$\mathrm{O}$ apoio decisivo do bloco constituído pelos países situados na Cortina de Ferro foi providencial para evitar a ruptura do edificio ameaçado. Negociando com habilidade, Halloran aceitou uma transição honrosa: mandato adicional de 2 anos, com a possibilidade de tutelar a própria sucessão. 
Em 1990, tendo como cenário uma lugoslávia em frangalhos, o inglês James Halloran transferiu o bastão para mãos seguras, as do holandês Cees Hamelink, seu vice-presidente.

\section{Consagração}

A estrela descendente de Gardel logo foi trocada pelo signo auspicioso de McLuhan. O Prêmio que o Governo do Canadá lhe outorgou em 1991 embutia os fluidos da poderosa galáxia vislumbrada pelo seu patrono.

Ele passou a fazer parte de uma galeria previamente integrada por 5 personalidades mundiais: o jornalista boliviano Luis Ramiro Beltran, (1983); o escritor italiano Umberto Eco (1985), o professor israelense Elihu Katz (1987) e o musicólogo francês Pierre Schaeffer (1989). escolha:

O comunicado emitido pelo Júri Canadense assim justificava a

"James D. Halloran tem feito importante e significativa contribuição ao campo da comunicação de massa. Ele foi diretor do Centre for Mass Communications Research da University of Leicester, Inglaterra, desde a sua fundção em 1966. Antigo Presidente da International Association for Mass Communications Research, seu trabalho girou em torno dos efeitos da televisão, delinqüência estimulada pela mídia, manifestações politicas, as demandas da pesquisa em comunicação e a comunicação para o desenvolvimento, através de várias entidades, dentre elas a International Association for Mass Communication Research, o Prix Jeunesse International, o Centro Internazionale Studi Famiglia in Milan, Unesco, o Council of Europe, que o tornaram uma figura reconhecida e respeitada na pesquisa em comunicação de massa."

Ele continuou a desfrutar o prestígio intelectual consolidado durante sua carreira singular, mesmo depois de se aposentar na Universidade de Leicester. 
Os indícios desse reconhecimento evidenciaram-se, agora, com a difusão mundial do seu necrológio. Periódicos digitais na Inglaterra, Espanha, Índia, Brasil, Canadá, Austrália, França etc. noticiaram sua morte e enalteceram sua trajetória intelectual.

\section{Vida e obra}

Quem foi James Halloran ? Como transcorreu sua história de vida? Que obra legou às novas gerações?

Sua vida privada é pouco conhecida. Sabe-se apenas que nasceu em Birstall, vilarejo próximo à cidade de Leeds, no Reino Unido. Estudou nas universidades de Leeds e Londres. Tem formação acadêmica na área educacional, com ênfase em gestão educativa e educação de adultos. Trabalhou inicialmente em programas de formação profissional e de reabilitação carcerária. Foi natural portanto o seu interesse pelo impacto da mídia na educação permanente dos jovens e adultos que sobrevivem à margem do sistema formal.

A experiência acumulada nesse setor o habilitou a participar de comitês de avaliação educativa da televisão inglesa, antes de enveredar pela carreira acadêmica. Fez parte do British Government's Television Research Committee e do Council of the Media Society do Institute of Journalists. Mais tarde, sendo também consultor da Comissão Mac Bride da UNESCO.

Roger Dickinson, seu colega no Centre of Media and Communication da University of Leicester, atribui o êxito da sua carreira acadêmica aos seguintes fatores.

"O sucesso de Jim deveu-se à habilidade para persuadir. potenciais doadores de recursos destinados a investimentos na pesquisa por ele conduzida ou realizada por seus colegas, consolidando desta forma o Centro de Leicester. Eram pesquisas relevantes para construir politicas e práticas midiáticas. Ele tinha igual capacidade para escolher a dedo jovens talentosos para a pesquisa, motivando alguns deles a se tornar intelectuais produtivos e criativos. Criando assim um ambiente que em 20 anos converteu-se em departamento modelo para Universidade de Leicester e um dos mais conhecidos e respeitados, em todo o mundo, no campo da mídia e da comunicação." . 
Por sua vez, o pesquisador alemão Juergen Wilke (Universidade de Mainz) destaca a atuação que ele teve na comunidade acadêmica da comunicação, recordando sua habilidade diplomática (Fonte: In Memory of Prof. James Halloran, www.iamcr.org):

"Eu o recordo deste a primeira conferência da IAMC a que compareci, em Varsóvia, 1978, onde equando me impressionou sua habilidade para apartar brigas homéricas entre partes conflagrada dentro da mesma organização. Ele foi um excelente negociador e ao mesmo tempo um pesquisador de vanguarda São inesqueciveis os estudos contidos no livro "Demonstrations and Communication", cujos resultados foram decisivos para a reavaliação da influência exercida pelos jornalistas na eclosão de eventos públicos.."

O legado bibliográfico de James Halloran é conjuntural, sem deixar de ser instigante, embora seu principal foco de análise se localize no impacto sócio-cultural da mídia, como bem evidencia o perfil accessível no portal Infoamérica (Universidade de Málaga, Espanha):

"En su larga bibliografía, cabe destacar: Television and delinquency, Leicester U. Press, 1970; The effects of television, Panther, Londres, 1970; Television for children and young people, European Broadcasting Union, 1970; Training in the critical reading of television language: The implication of media research for cultural policies, Council of Europe, 1974; Mass Media Education: Education for Communication and Mass Communication Research, con Marsh Jones, IAMCR/AIERI, Leicester, 1984; The Inoculation Approach. En Learning About the Media: Communication and Society, con Marsha Jones, UNESCO, París, 1986. En 1993, publicó As indústrias culturais e a integração latino-americana, Intercom, S. Paulo. En lengua española: Los efectos de la televisión, Editora Nacional, Madrid, 1974. En 1994 se publicó el libro homenaje al profesor Hallorand, editado por Cees J. Hamelink y Olga Linné, Mass communication research: on problems and policies, the art of asking the right questions (Ablex, Norwood, N.J.)" 


\section{Matizes}

Não obstante fosse considerado pela vanguarda da nova geração de exegetas do pensamento comunicacional como o nosso "último imperador", que reinou carismaticamente na comunidade acadêmica da área, até que os ventos da glasnost soprassem com vigor, o professor catalão Manuel Pares i Maicas não hesita em rotulá-lo ideológicamente como "partidário de la investigación critica" (Portal de la Comunicación, Barcelona, INCOM, 18/05/2007).

$\mathrm{Na}$ verdade, os destaques obtidos por James Halloran nos inventários das ciências da comunicação mostram-se compatíveis com a natureza polimorfa da sua produção científica. Vou tomar como referência uma fonte emblemática: Dennis McQuail - Mass Communication Theory, 3a. ed., London, Sage, 1994

McQuail inclui suas contribuições relevantes em duas correntes teóricas - os estudos seminais localizam-se no segmento dos "efeitos midiáticos", particularmente na fase 4, a dos "efeitos negociados"; enquanto isso, as pesquisas da maturidade são arroladas no segmento da "cultura midiática", pertencendo à tendência que defende a "fabricação dos eventos midiáticos".

Fora do universo britânico, a repercussão causada pelas teses de James Halloran tem caráter episódico, localizada no tempo. Por exemplo, em seu tratado Teorias de la Comunicación (Santiago, Universidad de Chile, 1997), Edison Otero não o inclui entre os autores proeminentes da área, embora tenha consultado alguns dos seus textos para a descrição e interpretação das principais correntes e exegetas, especialmente seu livro sobre os efeitos da televisão, traduzido para o espanhol em 1974, bem como os artigos em que atualizou o tema, difundidos através da revista norte-americana Journal of Communication.

Outro indicador sintomático da sazonalidade da sua influência acadêmica é oferecido pelos dois inventários que Journal of Communication efetuou no início das décadas de 80 e 90 para avaliar as tendências dominantes nas ciências da comunicação. No inventário de 1983 - Ferment in the Field - Halloran aparece significativamente, merecendo 6 citações, reverenciado por exegetas do "pensamento crítico": Tjhomaz Szecsko, Herbert Schiller, Dallas Smythe, Vicent 
Mosco, Thimothy Haight e Ithiel de Sola Pool. Todavia, no panorama de 1994 - Defining Media Studies - ele aparece como um grande ausente. Tal evidência traduz o seu afastamento gradativo do trabalho investigativo, nos anos em que presidiu a IAMCR, canalizando sua energia intelectual para consolidar a comunidade acadêmica da nossa área.

Em três momentos, a América Latina serviu como cenário na trajetória de James Halloran como líder da comunidade mundial de ciências da comunicação: Buenos Aires, Argentina (1972) testemunhou a sua ascensão ao comando da IAMCR; Caracas, Venezuela (1980) marcou seu apogeu presidencial, em plena sintonia com as teses da NOMIC, patrocinadas pela UNESCO; Guarujá, Brasil (1992) presenciou sua aclamação como Presidente Honorário da entidade, posto que compartilhou com Jacques Bourquin, também presente à conferência brasileira.

\section{Brasil}

14 Seu relacionamento com o nosso país deslanchou a partir de 1970, quando o conheci em Paris, na sede da UNESCO, durante um seminário internacional sobre mídia e violência. Naquela conjuntura, eu ocupava o cargo Diretor do Departamento de Jornalismo da Escola de Comunicações e Artes da Universidade de São Paulo.

Desde a sua fundação, a ECA-USP estava integrada à IAMCR, através de professores filiados à entidade, entre eles José Freitas Nobre, que acabava de defender tese de doutorado na Sorbonne, sob a orientação de Fernand Terrou. Pessoalmente, mantive contatos periódicos com os três primeiros presidentes da associação: o francês Fernand Terrou; o norte-americano Raymond Nixon e o suíço Jacques Bourquin.

Durante aquele seminário da UNESCO, James Halloran desempenhou papel proeminente, intervindo com freqüência nos debates. Figuras academicamente mais reconhecidas como por exemplo Elihu Katz e Bradley Greenberg ficaram em segundo plano. Ungido como relator do simpósio realizado pela UNESCO, no ano anterior, em Montreal, sobre o desenvolvimento da pesquisa em comunicação (UNESCO - Les moyens d 'information dans la societé, Paris, 1970), o professor inglês ocupava o centro das atenções. Demonstrava também 
afabilidade em relações aos neófitos, como era o meu caso. Tanto assim que demonstrou interesse pelo estudo que apresentei sobre os índices de violência na imprensa brasileira (José Marques de Melo-A Violência no Jornalismo Brasileiro, In: Estudos de Jornalismo Comparado, São Paulo, Pioneira, 1972, p. 173-270) e pelos trabalhos dos participantes de outras nações periféricas.

Confesso que não percebi os sinais da ofensiva, então em curso, para eleger Halloran como presidente da IAMCR. Nessa ocasião, Kaarle Nordestreng, discretamente começava a criar condições para a ascensão do mestre britânico. Tanto assim que, no ano seguinte, Halloran foi agraciado com o título de Doutor Honoris Causa pela Universidade de Tampére, Finlândia, preenchendo lacuna importante do seu currículo universitário.

Infelizmente, deixei de comparecer ao congresso da IAMCR em Buenos Aires, impedido pelas restrições instituidas pela ditadura brasileira para a participação de intelectuais em eventos internacionais. Aliás, a presença latino-americana nesse encontro foi diminuta, limitando-se quase que somente aos anfitriōes argentinos, sendo que a vanguarda nacional da pesquisa em comunicação se encontrava no exílio.

Acompanhei a distância o processo de legitimação de James Halloran como líder da IAMCR, através dos boletins que eram distribuídos periodicamente aos associados. E continuei lendo os ensaios que ele assinava ou as coletâneas que coordenava, através de traduções argentinas, como o precursor Los efectos de lãs comunicaciones de masas (Buenos Aires, Editorial JÁ, 1969). Ou então por intermédio das obras originais, como os seus clássicos estudos Attitude Formation and Change (Leicester University Press, 1970) e Dmonstrations and Communication (Londres, Penguin, 1970). Mais adiante, mantive em dia meu conhecimento sobre as pesquisas por ele coordenadas, entre as quais Television and Media Effect (Londres, BBTA, 1974) e Televison and Socialization Process in the Family (Munchen, Verlag Dokumentation, 1975).

\section{Caminhos cruzados}

Só voltei a cruzar os caminhos percorridos por James Halloran em 1988, durante o tumultuado congresso de Barcelona, quando seu 
"império" estava por um fio. Naquela ocasião, a candidatura do Brasil para sediar um dos próximos congressos da IAMCR foi mais uma vez descartada, como já havia ocorrido no congresso da Índia, por iniciativa do professor Fernando Perrone, que se vinculou à entidade durante o seu período de exílio na França.

Como as perspectivas para garantia de condições adequadas à aceitação do Brasil como sede do encontro de 1992 mostravam-se promissoras, tendo em vista a nossa transição democrática, selada pela Constituição de 1988, solicitei uma audiência ao Presidente da IAMCR, em nome da INTERCOM - Sociedade Brasileira de Estudos Interdisciplinares da Comunicação. Vali-me dos préstimos oferecidos por Peggy Gray, sua secretária, mas que em realidade funcionava como uma espécie de "eminência parda" da IAMCR. Halloran se mostrou simpático e me explicou todos os procedimentos para obter o endosso da diretoria e a aprovação da pleito brasileiro pela assembléia da entidade.

Dois anos depois, em Bled, então Iugoslávia, liderei uma expressiva delegação brasileira ao congresso bienal da IAMCR (José Marques de Melo, og. - Communication and Democracy, São Paualo, ECA-USP, 1991). O apoio de Halloran à candidatura do Brasil para sediar o congresso de 1992 foi decisiva. Ele concluía sua gestão como presidente da IAMCR, demonstrando capacidade de negociação e poder de influência sobre a assembléia dos sócios.

Formulei, naquele momento, convite para que fizesse a conferência de abertura do XII Congresso Brasileiro de Ciências da Comunicação, agendado para setembro de 1991, em Florianópolis, Santa Catarina. Ele aceitou de bom grado e no ano seguinte proferiu instigante aula magna sobre o tema "As indústrias culturais e a integração latino-americana: o que se pode aprender a partir da experiência européia".

Sua resposta foi honesta e cristalina: "em termos de aplicação direta, talvez não haja tantos ensinamentos a serem extraídos da experiência européia que sejam relevantes para vocês da América Latina", pois "as transferências transculturais nessa área exigem muita cautela". Sua justificativa mostrou-se coerente e consistente do ponto de vista histórico: "Um passado caracterizado por facções divergentes mais preocupadas com as vantagens do que com a precisão, e muito mais preocupadas com a ideologia do que com a informação e a 
introvisão." Nesse sentido é que ele recomenda "estudos disciplinados e sistemáticos, em que as perspectivas históricas, econômicas e sociais mais amplas recebam a devida atenção, e os problemas, conceitos e termos sejam formulados e definidos com maior cuidado do que no passado."

No ano seguinte, ele voltaria ao país, para participar, como convidado especial, do congresso do Guarujá, onde teve uma atuação muito discreta, quase protocolar. Aliás, essa conduta foi mantida nos congressos subseqüentes: Seul (1994), Sydney (1996), Glasgow (1998).

\section{Epílogo}

Desde 1991, quando se aposentou das atividades docentes na Universidade de Leicester, Halloran foi se afastando pouco a pouco do convívio acadêmico, sem perder o contato epistolar com a vanguarda da IAMCR. Em 2004, quando o congresso voltou a se realizar no Brasil, desta vez em Porto Alegre, sua ausência foi notada. Justificativa: as condições de saúde já não lhe permitiam viagens tão exaustivas.

Através de Kaarle Nordestreng, que está escrevendo uma História da IAMCR, me chegaram as últimas notícias de James Halloran, bem como dos outros ex-presidentes, que ele vem entrevistando pessoalmente.

Havia a esperança de que Halloran pudesse participar de uma teleconferência, para celebrar os 50 anos de fundação da IAMCR, dialogando com sócios da sua geração. Sua morte, em maio deste ano, inviabilizou tal evento. Em sua homenagem foi realizada uma Sessão Especial, da qual participaram vários congressistas.

Existe, agora, a expectativa de publicação do livro de memórias a que se vinha dedicando ultimamente. Esse texto talvez seja elucidativo para restabelecer a verdade dos fatos, separando os relatos lendários dos testemunhos factuais. Ou melhor, permitindo discernir os liames que separam o homem do mito.

\section{Fontes consultadas}

Dziki, S.; Maczuga, J; Pisarek, W. Who's who in mass communication, Munchen, Saur 
Halloran, James 1970 - Lês moyens d'information dans la societé - Necessite de développer la recherche, Paris, UNESCO

Hamelick, Cees and Nordestreng, Kaarle. 2007-IAMCR History in a nutshell, www.iamcr.org (Back to the future)

Kunsch, Margarida. 1993 - Indústrias culturais e os desafios da integração latino-americana, São Paulo, Intercom

Levy, Mark and Gurevich, Michael. 1994 - Defining Media Studies, New York, Oxford

Marques de Melo, José. 2007 - História do Pensamento Comunicacional, $2^{\text {a }}$. ed., São Paulo, Paulus

McQuail, Dennis. 1994 - Mass Communication Theory3a. e., London, Sage

Otero, Edison. 1997 - Teorías de la Comunicación, Santiago, Universidad de Chile

Schramm, Wilbur and others. 1983 - Ferment in the field, Philadelphia, Annenbeg School Press 